\title{
Aplicação de redes neurais artificiais em processo de destilaçáo de óleo essencial
}

\author{
Ciro José Jardim de Figueiredo ${ }^{1}$ \\ Milton Helio Lima da Silva \\ Fabiano Cordeiro Moreira ${ }^{3}$
}

\begin{abstract}
Resumo: Na Amazônia, dentre as diferentes espécies vegetais destaca-se Piper aduncum L., rica em óleo essencial cujo mesmo é usado como bioinseticida. Neste sentido, este estudo objetivou prever um dos produtos gerados da destilação, em um sistema agroindustrial da espécie, usando Redes Neurais Artificiais (RNA's). Foram coletadas as seguintes variáveis de entrada: quantidade de biomassa e tempo de destilaçáo e a variável de saída, Água de cheiro para o treinamento da rede pelo método backpropagation. Para alcance da eficácia da rede, determinou-se um menor erro e uma maior aproximação entre os dados reais e os estimados, sendo esta aproximação avaliada pelo valor $r$ de correlação. $\mathrm{O}$ método demonstrou uma aproximação maior com os valores reais quando comparados com outro estudo, que também utilizou os mesmo dados, porém aplicando o método de regressão múltipla.
\end{abstract}

Palavras-chave: Óleos essenciais, Redes Neurais, Agroindústria.

Abstract: In the Amazon region, among different plant species stands Piper aduncum L., rich in essential oil which it is used as insecticide. Thus, this study aimed to provide a distillation of the products generated in an agro-industrial system of the species, using Neural Networks (NN). Were collected the following input variables: mount of biomass and time distillation and the output variable, "water smell", to train the network was used the method backpropagation. To reach the efficiency of the network, was determined a minor error and a closer relationship between the estimated data and actual data, such approximation was evaluated by the $r$ value of correlation. The method showed a closer approximation to the actual values when compared with another study that also used the same data, but applying the method of multiple regression.

Keywords: Essential oils, Neural Networks, Agribusiness.

\footnotetext{
Universidade Federal de Pernambuco, Mestrando em Engenharia de Produção (ciro.figueiredo@ufpe.br)

Museu Paraense Emílio Goeldi, Pesquisador Adjunto (miltonhelio@museu-goeldi.br)

Centro Universitário do Pará, Docente (fabianomoreira@plugplay.br)
} 


\section{INTRODUÇÃO}

Atualmente, o Brasil vem apresentando grande crescimento e inovaçáo no setor agrícola, área que demanda cada vez mais por tecnologia de ponta que possa auxiliar na reduçáo de custos e aumento da produtividade. Neste mesmo eixo, Farina (1999) ressalta que deve haver uma competitividade de negócios aliada ao desenvolvimento agrícola, em virtude da presença do país na economia internacional, caso contrário ocorrerá à estagnação e declínio econômico do setor.

Aliado a este contexto, se sobressaem os investimentos em técnicas na agropecuária que se expandem, contribuindo em sistemas Agrosustentáveis, Manejo de solos e pragas fitopatológicas, biotecnologia, otimização de processos produtivos, etc (Batalha et al. 2009). Uma destas técnicas, segundo Pandorfi et al. (2011), é o uso de Redes Neurais Artificiais (RNA's) para a previsão de informaçóes, sendo um diferencial para o gestor, tornando-se uma ferramenta para a tomada de decisão no ambito agrícola.

Segundo Haykin (2001) o uso das RNA's esta associado a vantagens como: aplicação em tempo real, capacidade de autoadaptação, redução de falhas, resolução de problemas de forma ágil e sem necessidade de implementação de regras. Ma e Khorasni (2004) definem uma rede neural, como um método rápido de ser executado que classifica padróes, capaz de identificá-los e associa-los em grupos com semelhanças em comum, além de aproximar funçôes para "aprendizagens" onde a construçáo e o uso de modelos matemáticos torna-se complexo e limitado.

Pandorfi et al. (2011) ainda destacam o uso das redes neurais no controle de elementos meteorológicos em instalaçôes zootécnicas para resposta ao comportamento postural e adequaçáo ao manejo com base em variáveis fisiológicas, em função das características nutricionais para determinadas criaçôes. Outra aplicação é quanto a classificação no uso da terra com diferentes níveis de degradação em pastagens para avaliar danos causados em áreas de produção bovina (Chagas et al. 2009). Assim, seu uso torna-se vasto e promissor em um setor que cresce significativamente.

$\mathrm{Na}$ região Norte do país, também vem-se obtendo destaque na agropecuária, seja pela necessidade de novas terras que possam ser produtivas, seja por questôes logísticas relacionadas a transportes e escoamento da produçáo. Neste sentido, aumenta cada vez mais a perspectiva de implantação de um sistema agrícola baseado na exploraçáo de óleo essencial rico em Dilapiol, extraído de uma espécie nativa da Amazônia, chamada de Piper aduncum L., para produção em grande escala.

O sistema em estudo apresenta como diferencial, a inovação de um óleo que não agride o meio-ambiente, com propriedades que podem ser direcionadas no controle de fitopatógenos que prejudicam diferentes produçóes agrícolas, acarretando inúmeros prejuízos aos produtores. Portanto, inúmeros testes já foram realizados com resultados positivos que comprovam a eficiência do óleo (Almeida et al. 2009; Bastos, 1997; Estrela et al. 2006; Fazolin et al. 2005; Silva et al. 2007).

Além disso, estudos vêm sendo conduzidos nos últimos três anos, no que diz respeito ao beneficiamento da cadeia produtiva, com indicadores que viabilizam a produção, como: baixo custo envolvido, produtividade elevada e nível de agressão ambiental reduzido (Figueiredo, et al. 2010a; Figueiredo et al. 2010c). Sendo o sistema constituído em três etapas sequenciais: produção de biomassa de $P$. aduncum L., destilação do óleo e efetivação do uso.

Segundo Figueiredo et al. (2010b) a fase de destilação é a mais complexa, pois a etapa exige um rigoroso controle dos parâmetros do sistema para que sejam mantidos os níveis ideais de produção. Porém, pouco se encontra na literatura a respeito da otimização do processo de destilaçáo.

Eikani et al. (2007) conduziram estudos que visaram comparar diferentes processos de destilação com folhas de Coriandrum sativum L., demonstrando que o processo de hidrodestilação possui altos níveis de extração de óleo. Já El-Seedi et al. (2010) realizaram estudos para verificar em que partes de Psoralea pubescence havia maiores concentrações de seu óleo essencial. Em síntese, os estudos de destilação visam verificar qual o melhor método, ou, em que partes de uma espécie vegetal se concentra os altos teores de óleo essencial.

Portanto, o objeto deste estudo é a análise de um dos produtos ("água de cheiro") resultante da etapa de destilação do óleo, usando RNA's para prediçáo do mesmo, com base em variáveis que possam auxiliar na previsão dos dados. As informaçôes obtidas são referentes a um estudo 
anterior que usou como ferramenta a técnica de regressão múltipla. Ao final foram comparados os resultados pelos dois modelos.

\section{DESCRIÇÃO DO PROCESSO}

O processo corresponde a etapa dois de produçáo, sendo o mais importante e a que exige maior atençáo no que diz respeito aos parâmetros de controle operacional. A etapa de Destilaçáo tem início após a secagem das folhas de $P$. aduncum L., em que o material é levado para o destilador para extração do óleo e a "água de cheiro".

O Destilador é composto por um tambor principal[1] onde o material é armazenado, e que está suspenso sobre a caldeira[2] que recebe lenha para ser queimada como forma de combustível. Há duas entradas de água: a primeira[3] injeta água para o aquecimento e a segunda[4] para o resfriamento. No resfriamento, o óleo desce pelo cano de escape[5] onde é coletado.

O seu funcionamento se dá pela queima do combustível, que induz a água para o estado de ebulição, evaporando e consequêntemente "arrastando" o óleo consigo. Em seguida, quando a água no estado de vapor em conjunto com o óleo passam para o cano de escape, ambos são resfriados e ocorre o processo inverso, e a água retorna ao estado líquido decaindo na extremidade do mesmo, misturada com o óleo. Após a saída do líquido contendo água e óleo, deve-se aguardar um tempo de 30 minutos para decantação do óleo e separação da água. Do excesso que não se consegue separar o óleo da água dá-se o nome de "água de cheiro", segundo produto oriundo do processo usado como biodefensivo e foco deste estudo. A Fig. 1 apresenta uma ilustraçáo do aparelho de destilação usado.

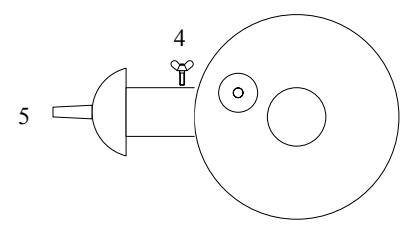

a)

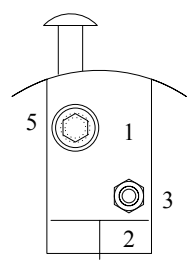

b)
Figura 1 - Ilustraçấo do aparelho de destilaçâo utilizado. a) vista superior e b) vista frontal.

Os parâmetros de controle são a quantidade de biomassa inserida no destilador e o tempo de destilação, e que são fundamentais para o controle da quantidade de "água de cheiro" que sai do sistema. A vazão d'água e a temperatura do sistema, também são variáveis que contribuem para a determinação da variável em estudo, todavia, o seu controle é viável somente com aparelhos específicos e também não é o foco deste trabalho.

\section{METODOLOGIA}

Os dados obtidos neste estudo foram coletados no processo de destilação do óleo essencial de $P$. aduncum L. no período de 2008 a 2010, nas instalaçóes localizada no município de $\mathrm{St}^{\circ} \mathrm{An}$ tônio do Tauá ( $1^{\circ} 02^{\prime} \mathrm{S}$ e $\left.48^{\circ} 13^{\prime} \mathrm{W}\right)$. Local onde ocorrem os cultivares da espécie e todo o processo de beneficiamento.

Do resultado do processo de beneficiamento da biomassa são retirados dois produtos: o óleo propriamente dito e a "água de cheiro", composição de água com particulados de óleo onde não é possível a decantação do mesmo. Todavia, possuem as mesmas finalidades de uso no combate a fitomoléstias. O aparelho para destilaçáo usado, foi o modelo por arraste a vapor, tambor único para evaporaçáo do óleo e decantação por resfriamento.

As variáveis de entrada foram a quantidade de biomassa $(\mathrm{Qm})$ e o tempo de destilação $(\mathrm{Td})$ e a variável de saída foi a "água de cheiro". As coletas ocorreram de forma aleatória no período de funcionamento do destilador. Denomina-se um período de destilação o tempo total de seu funcionamento que dura de $24 \mathrm{~h}$ a $36 \mathrm{~h}$ contínuas (com pausa para troca de biomassa). Cada parada para troca de biomassa corresponde a uma bateria de destilação, processo que consiste na colocação de biomassa (variando de $5,5 \mathrm{~kg}$ a $10,4 \mathrm{~kg}$ ) e a retirada da mesma em um intervalo de tempo que varia $\mathrm{de} 2 \mathrm{~h}$ a $4 \mathrm{~h}$. Sendo que as coletas ocorreram por bateria de destilação.

Um banco de dados foi criado para o armazenamento das 30 amostras retiradas, sendo definidas ao acaso 15 conjuntos para treinamento (Qm, Td e "água de cheiro") e 15 para validação. Os dados de saída foram normalizados entre [0, 1] para criação da RNA e como exigência pelo programa utilizado, demonstrado pela seguinte equação:

$$
\mathbf{X}_{\text {inor. }}=\frac{\mathbf{X}_{\mathrm{i}}}{\sum_{\mathrm{i}=1}^{\mathrm{n}} \mathrm{x}_{\mathrm{i}}}
$$


em que: $\mathrm{x}_{\text {inor. }}$ é o valor normalizado, $\mathrm{x}_{\mathrm{i}}$ é o valor a ser normalizado e $\sum_{\mathrm{n}=1} \mathrm{x}_{\mathrm{i}}$ a soma de todos os elementos que serão normalizados.

$\mathrm{O}$ algoritmo de aprendizado usado para o treinamento da rede foi o backpropagation (BP), com regra de aprendizado Widrow-Hoff que minimiza o erro pelo Erro Quadrático Médio (EQM) buscando um conjunto de pesos nas conexóes de neurônios que reduza este erro.

A arquitetura da rede BP foi composta por dois neurônios na camada de entrada, quatro neurônios ocultos com uma função logística e um neurônio na camada de saída, também com uma função lógística, a topologia segue descrita na Fig. 2. Na camada de entrada foram usados os dados de quantidade de biomassa e tempo de destilação.

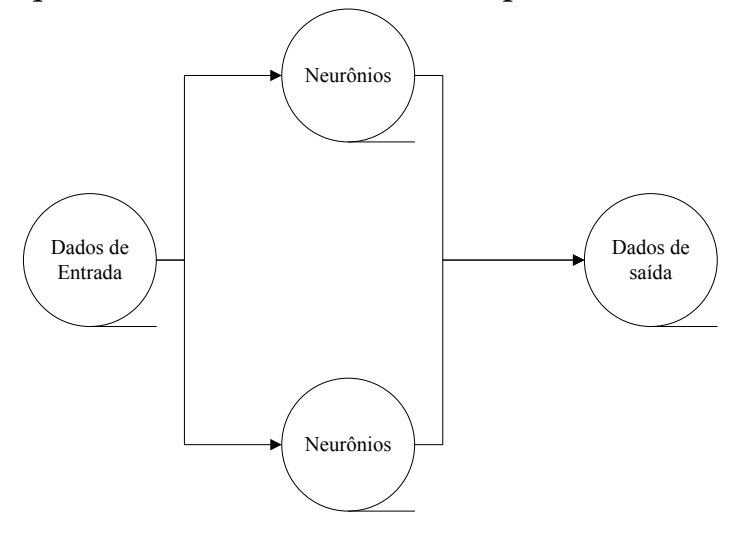

Figura 2 - Arquetipo para a rede empregada.

O algoritmo RB foi constítuido das seguinte etapas:

a) inserir os dados de entrada e saída da rede composta pelo conjunto de treinamento;

b) ativar os parâmetros da rede e inicialização dos pesos, descritos na Tab. 1;

c) calcular o EQM para a camada de saída através da diferença entre o valor real $\left(y_{i}\right)$ e o valor estimado $\left(\mathrm{y}_{\text {est. }}\right)$ pela rede neural para a minimização, demonstrado na equação 2 ;

$\mathrm{EQM}=\sum \frac{\left(\mathrm{y}_{\mathrm{i}}-\mathrm{y}_{\mathrm{est}}\right)^{2}}{\mathrm{n}}$

d) ajustar os pesos da camada de saída $\left(\ddot{A ̈}_{\mathbf{W}_{\mathbf{i}}}^{0}\right)$ pelo seguinte modelo referente a equaçáo 3 ;

$\Delta \mathrm{W}_{\mathrm{i}}^{0}(\mathrm{k}+1)=\left(\mathrm{y}_{\mathrm{i}}-\mathrm{y}_{\mathrm{est} .}\right) \mathrm{f}_{\mathrm{p}}^{\mathrm{o}^{\prime}}\left(\right.$ net $\left._{\mathrm{kj}}^{\mathrm{o}}\right) \mathrm{i}_{\mathrm{kj}}$

em que $\eta=$ taxa de aprendizado; $f=$ função contínua derivável e net = estado de ativação (funções de ativação).

e) minimizar o EQM para comparação com o va- lor desejado. Caso não seja alcançado o valor do erro esperado retornar ao passo b.

Tabela 1 - Parâmetros de treinamento para o algoritmo backpropagation.

\begin{tabular}{|c|c|}
\hline $\begin{array}{c}\text { Parâmetro } \\
(\eta)\end{array}$ & Valor \\
\hline Erro (EQM) & $2 \times 10^{-6}$ \\
\hline $\begin{array}{c}\text { Neurônio na camada } \\
\text { oculta }\end{array}$ & 4 \\
\hline $\begin{array}{c}\text { Função de transferência } \\
\text { na camada oculta }\end{array}$ & Logística \\
\hline $\begin{array}{c}\text { Função de transferência } \\
\text { na camada de saída }\end{array}$ & Logística \\
\hline
\end{tabular}

Para avaliar o desempenho da rede adotou-se a combinação entre o mínimo EQM e o número de ciclos (epochs) como critérios de parada do treinamento da rede. Quando se atingiu o menor EQM em um menor número de ciclos o treinamento foi encerrado. Após estas etapas, foram inseridos os outros 15 dados de entrada contidos no banco de dados (quantidade de biomassa e tempo de destilação) para avaliação do treinamento e posterior comparaçáo dos resultados da previsão realizada pela RNA com modelo de regressão desenvolvido em estudos anteriores.

Para a solução da RNA utilizou-se o Neural Network Toolbox do Matlab 7.5 pacote que contém soluçôes para redes neurais com funçôes já definidas.

\section{RESULTADOS E DISCUSSÃO}

O parâmetro adotado inicialmente para a taxa de aprendizado foi de 0,1 até 1 , porém como houve dificuldades na busca pelo mínimo EQM, o algoritmo de treinamento BP foi alterado para BP com taxa de aprendizado adaptativa e momentum adaptativo. Assim, quando a taxa de aprendizado foi 1, o alcance do EQM ficava distante e quando o valor era de 0,1 a taxa de aprendizagem ficava lenta, resultado semelhante encontrado no estudo conduzido por Pandorfi et al. (2011).

Outro ponto semelhante encontrado, reportado também por Pandorfi et al. (2011) é a di- 
ficuldade em se definir os parâmetros da rede, pois os esforços para suas alteraçóes são exaustivos e demandam grande parte do tempo no desenvolvimento da RNA. Em virtude de qualquer parâmetro, que quando alterado, resultou em variaçóes significativas nos resultados.

As variaçóes realizadas nas quantidades de neurônios na camada intermediária, também impactaram na redução do EQM. Quando foram inseridos de 10 a 25 neurônios na camada intermediária a rede náo conseguiu aproximar o EQM esperado, porém os neurônios uma vez reduzidos para 4 localizaram o erro ideal.

Segundo Artero (2009), não existe uma regra única que determine o número de neurônios na camada oculta, entretanto o autor indica que esta determinação seja realizada com base na média geométrica do número de neurônios nas camadas de entrada e de saída.

Portanto, esta combinação entre a taxa de aprendizado e o número de neurônios ocultos identificou o EQM esperado de 2 × 10-6 em 5055 ciclos, onde cada ciclo é a "apresentação" do conjunto de treinamento para a rede. $\mathrm{O}$ valor do erro também se iguala aos mesmos resultados encontrados por Figueiredo et al. (2010b) e que utlizaram a técnica de regressão múltipla. A redução do erro segue na Fig. 3 a seguir.

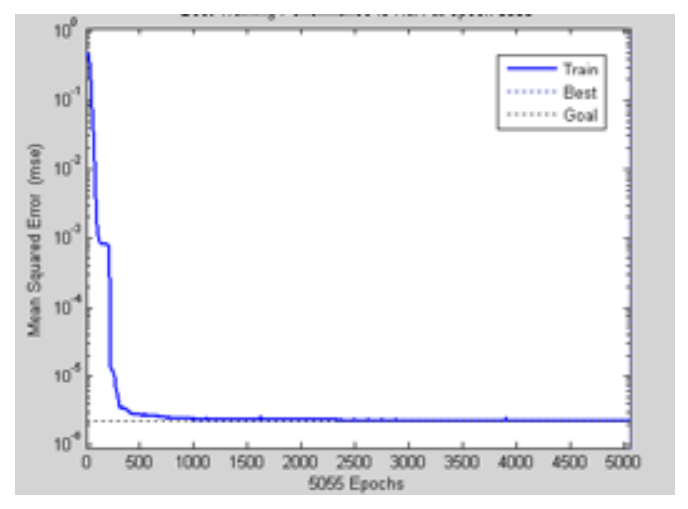

Figura 3 - Minimização do Erro Quadrático Médio.

Os dados previstos pela rede, quando comparados com os dados reais do problema apresentaram elevado coeficiente de correlaçáo (r), igual a 0,924 , relacionando os pares ordenados do valor real com o previsto, indicando poucas variaçóes mínimas nas quais a rede não conseguiu treinar. Por outro lado, a regressáo entre o valor estimado e o valor real, determinada pelo valor da função de regressão indicou um valor de correlação inferior, equivalente a 0,894 , ou seja, o modelo de regressão não conseguiu explicar as variaçóes com um percentual inferior ao gerado pela rede neural. As Fig. 4 e 5 abaixo apresentam estas regressóes.

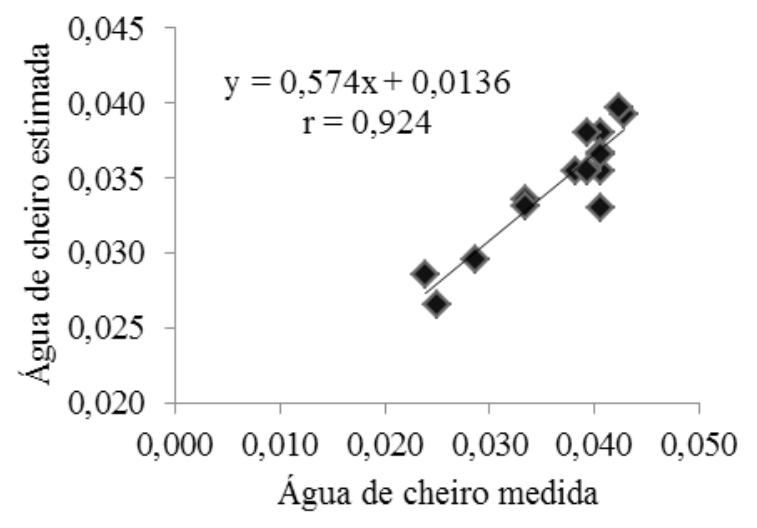

Figura 4 - Valor real versus estimado através de RNA para a "Água de cheiro".

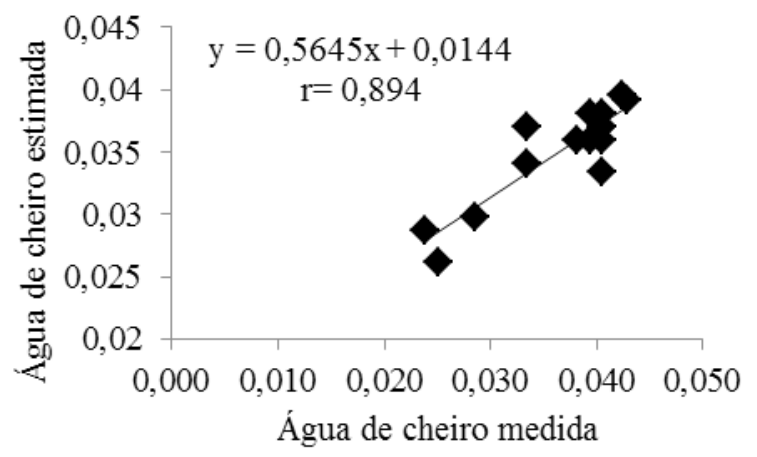

Figura 5 - Valor real versus estimado através da regressão múltipla para a "Água de cheiro".

Entretanto, Figueiredo et al. (2010b) encontraram resultados para o mesmo problema por Regressão múltipla para a predição, utilizando todos os dados, um aumento no valor da correlação, passando para 0,934 , o que implicou em uma maior aproximaçáo dos dados reais com os previstos. Isto é justificado pelo fato de haver um modelo preciso com parâmetros estabelecidos para as estimativas (Xin, 1999). Mas, quando os dados foram analisados parcialmente houve uma reduçáo deste coeficiente, como demonstrado anteriormente.

A previsão por meio do conjunto de treinamento indicou um acerto bem próximo do real, indicando a possibilidade do uso da rede para previsão da quantidade de "água de cheiro" gerada pelo processo. $\mathrm{O}$ uso deste controle de previsão serve para inserir as quantidades ideais de material (quantidade de biomassa) no processo de destila- 
ção e a duração (tempo da bateria) da destilação, permitindo uma quantidade ideal do produto beneficiado. Os resultados, também corroboram com a justificativa apresentada por Martínez-Estudillo et al. (2006) que afirmam que uma melhor aproximação torna-se inviável devido a falta de dados. Ou seja, mais dados poderiam induzir a rede a superar o EQM da regressáo. A Fig. 6 seguinte apresenta a previsão baseada na RNA.

O modelo de regressão também previu com as mesmas proximidades da rede usada, indicando não haver tantas distinções quanto ao uso de ambas. A regressão se mostra viável, principalmente pelo fato de apresentar uma equaçáo exata com parâmetros determinados. Entretanto, o uso da Rede permite alterações na sua arquitetura podendo haver melhorias no processo de aprendizado, logo superando a técnica de regressão. A Fig. 7 apresenta o modelo de previsto pela regressáo

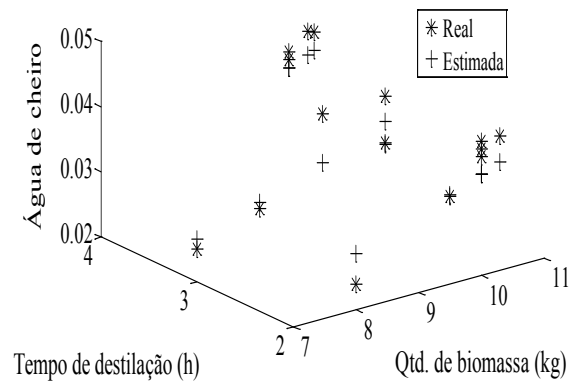

Figura 6 - Água de cheiro real e estimada em função das variáveis de entrada determinada pela RNA.

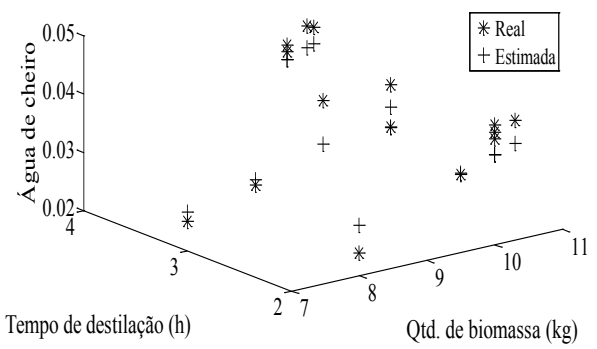

Fonte: Figueiredo et al. 2010b.

Figura 7 - Água de cheiro real e estimada em função das variáveis de entrada determinada pela Regressão.

\section{CONCLUSÃO}

O uso de Redes Neurais Artificiais se mostrou eficaz para previsão da quantidade de "água de cheiro" em funçáo das variáveis quantidade de biomassa e tempo de destilação. Apesar da convergência da rede ter ocorido em 5055 epochs, fato que não impediu o alcance do EQM esperado, uma vez que o mesmo foi igualado ao erro da regressão.

Pelo fato do erro da regressão ser baixo em função de haver uma equação objetiva com parâmetros definidos, era esperado previamente que a RNA náo conseguisse obter a mesma eficiência. Entretanto, a minimização do erro esperado foi igualada em virtude das inserçóes adequadas da quantidade de neurônios na camada intermediária e da taxa de aprendizado adaptativa. Além do maior poder de correlaçáo identificado entre os valores reais e os estimados.

Portanto, o uso da técnica de Redes Neurais apresentou um bom resultado para o problema em estudo, pois o intenso controle operacional necessário para destilação do óleo e da "água de cheiro", não permitem uma ênfase no estudo de variáveis mais difíceis de serem controladas (temperatura e vazão d'água). Logo, a técnica se mostrou apropriada para determinaçáo da variável de saída, com base em duas variáveis que são controladas ao longo de todo o processo e não exige nem um esforço operacional extra.

Para estudos futuros pretende-se estabelecer outras variáveis que também possam influenciar no processo, bem como a coleta de mais dados para generalização do problema.

\section{AGRADECIMENTOS}

Os Autores agradecem ao Conselho Nacional de Desenvlvimento Científico e Tecnológico $(\mathrm{CNPq})$ e a Fundação de Amparo à Pesquisa no Estado do Pará (FAPESPA).

\section{REFERÊNCIAS}

ALMEIDA, R. R. P.; SOUTO, R. N. P.; BASTOS, C. N.; SILVA, M. H. L.; MAIA, J. G. S. (2009) Chemical variation in Piper aduncum and biological properties of its dillapiole-rich essential oil. Chemistry \& Biodiversity, Vol.6, n.9, p. 14271434.

ARTERO, A. O. (2009) Inteligência artificial: teórica e prática. São Paulo: Livraria da Física.

BASTOS, C. N. (1997) Efeito do óleo de P. aduncum L. sobre Clinipellis perniciosa e outros fungos 
fitopatopênicos. Fitopatologia brasileira Vol. 3, p.441-443.

BATALHA, M. O.; CHAVES, G. L. D.; SOUZA FILHO, H. M. (2009) C\&T e I para a produção agropecuária brasileira: mensurando e qualificando gastos públicos. Revista de Economia e Sociologia Rural Vol.47, n.1, p.123-145.

CHAGAS, C. S.; VIEIRA, C. A. O.; FERNANDES FILHO, E. I.; JÚNIOR, W. C. (2009) Utilização de redes neurais artificiais na classificação e niveis de degradação em pastagens. Revista Brasileira de Engenharia Agrícola, Vol.13, n.3, p.319-327.

EIKANI, M. H.; GOLMOHAMMAD, F; ROWSHANZAMIR, S. (2007) Subcritical water extraction of essential oils from coriander seeds (Coriandrum sativum L.). Journal of Food Engineering, Vol.80, n.2, p.735-740.

EL-SEEDI, H.; ZAYED, M.; ROSHDY, S.; SALEM, M.; HAWATA, M.; EL-ESSAWY, F.; ELBARBARY, M.; EL-KOUSY, S. (2010) Analysis of the essential oil from the aerial parts of Psoralea pubescence (Miq.) Standl its antibacterial activity. Medicinal Chemistry Research, Vol.19, n.9, p.1036-1042.

ESTRELA, J. L. V.; FAZOLIN, M.; CATANI, V.; ALÉCIO, M. R.; LIMA, M. S. (2006) Toxicidade de óleos essenciais de Piper aduncum e Piper hispidinervium em Sitophilus zeamis. Pesquisa Agropecuária Brasileira, Vol. 41, n.2, p.217-222.

FARINA, E. M. M. Q. (1999) Competitividade e coordenaçâa de sistemas agroindustriais: um ensaio conceitual. Gestão \& Produção Vol.6, n.3, p.147161.

FAZOLIN, M.; ESTRELA, J. L. V.; CATANI, V.; LIMA, M. S. e ALÉCIO, M. (2005) Toxicidade do óleo de Piper aduncum L. a adultos de Cerotoma tingomarianus Bechyné (Coleoptera: Chrysomelidae). Neotropical Entomology, Vol. 34, n.3, p.485-489.

FIGUEIREDO, C. J. J.; SILVA, M. H. S.; CARVALHEIRO, B. C.; PEREIRA, W. M. A.; CHAVES, A. L. F. (2010a) Utilização de técnicas operacionais para otimizaçáo dos processos de corte e colheita de Piper aduncum L. INGEPRO Vol. 2, n.3, p.37-45.

FIGUEIREDO, C. J. J.; SILVA, M. H. S.; CARVALHEIRO, B. C.; PEREIRA, W. M. A.; CHAVES, A. L. F. (2010b) Regressão múltipla aplicada a um processo de destilaçáo por arraste a vapor de óleo essencial de Piper aduncum L. In: ENCONTRO NACIONAL DE ENGENHARIA DE PRODUÇÃO, São Carlos: UFSCAR.

FIGUEIREDO, C. J. J.; SILVA, M. H. L. SARMENTO, B. C.; PEREIRA, W. M.; FREIRES, E. S. (2010c) Avaliação dos processos de destilaçâo em nivel piloto de produçâo da espécie Piper aduncum L., planta produtora de óleo essencial. In: SIMPÓSIO DE ENGENHARIA DE PRODUÇÃO, Bauru: UNESP.

HAYKIN, S. (2001) Redes neurais: princípios e práticas. Porto Alegre: Bookman.

MA, L.; KHORASANI, K. (2004) New training strategies for constructive neural networks with application to regression problems. Neural Networks, Vol. 17, n.4, p.589-609.

MARTÍNEZ-ESTUDILLO, A.; MARTÍNEZESTUDILLO, F. M.; HERVÁS-MARTÍNEZ, C.; GARCÍA-PEDRAJAS, N. (2006) Evolutionary product unit based neural networks for regression. Neural Network, Vol.19, n. 4, p.477-486.

PANDORFI, H.; SILVA, I. J. O.; SARNIGHAUSEN, V. C. R.; VIEIRA, F. M. C.; NASCIMENTO, S. T.; GUISELINI, C. (2011) Uso de redes neurais artificiais para predição de indices zootécnicos nas fases de gestação e maternidade na suinocultura. Revista Brasileira de Zootecnia, Vol.40, n.3, p.676-681.

SILVA, W. C.; RIBEIRO, J. D.; SOUZA, H. E. M.; CORRÊA, R. S. (2007) Atividade inseticida de Piper aduncum L. (Piperaceae) sobre Aetalion sp. (Hemiptera: Aetalionidae), praga de importância econômica no Amazonas. Acta Amazonica, Vol.37, n.2, p.293-298.

XIN, H. (1999) Assessing swine thermal comfort by image analysis of postural behaviors. Journal of Animal Science, Vol.77, n.2, p.1-9 